\title{
Research on Individual Privacy Information Protection in Process of Information Resources Commercialization
}

\author{
${ }^{1}$ Xiaoming Meng, ${ }^{2}$ Song LIU, ${ }^{3}$ Haiying Hua \\ Information Science School \\ Guangdong University of Business Studies \\ Guangzhou, Guangdong, 510320, P.R. China \\ 1am669y@163.com, ${ }^{2}$ j803h@163.com, ${ }^{3}$ hrice77@sina.com
}

\begin{abstract}
Defined the concept of information resources commercialization, depicted commercialization process of information resources, analyzed the driving factors of information resources commercialization. Realistic cases and survey results show that the security situation of individual privacy information during the process of information resources commercialization is worrying. The analysis on the behaviors which invades individual privacy information in the information resources collection and development and utilization shows that information resources commercialization process aggravates the individual privacy information leakage. In order to protect the individual privacy information safe, we gave out four important measures: to establish and improve relevant laws and regulations, to strengthen industry self-discipline and of information resources development and utilization norms, to improve individual citizen's awareness and skills of protecting individual privacy information, to strengthen construction of social credit system, to implement open credit rating system.
\end{abstract}

Keywords- Information resources; Commercialization; Individual privacy; Privacy information

\section{INTRODUCTION}

In modern information society, there are three kinds of resources such as information, energy and materials. Information resource is becoming an important strategic resource of national economic and social development. Its development and utilization is the core content in the whole social informatization, and it is the important way to realize social and economic development. Social informatization and modern information service industry developing speed up the trend of information resources commercialization. But there are many leakages existing in relevant laws and regulations, social credit system, individual safety consciousness and skills, information technology itself, self-discipline in information service industry etc. These lead to some individuals, businesses or organizations illegally collect, steal, monitor, intercept, destruct and spread individual privacy information to get profit or interest. These invade individual privacy information right, disturb the normal market order of information resources development and utilization, and which restrict the process of social informatization and modern information service industry healthy development. This is not conducive to social harmony and stability.

\section{INFORMATION RESOURCES COMMERCIALIZATION}

\section{A. Concept of Information Resources Commercialization}

Information resources refer to all the available information which stores in certain carriers (include human brain) by using symbols, and by through with a series of understanding and creative process. Now the connotation of information resources is constantly expanding while the society is developing. It includes not only the growing science information resources but also the social science information resources [1]. Comparing with natural resources and material resources, information resources can be used repeatedly. Its value is realized in being used, the using of it has a strong goal orientation, different information used by different users reflect different value. It has integration characteristic, its retrieval and utilization are not affected and constrained by time, space, language, region and industry. It is social wealthy, any person can not buy the usage right for full or permanently. It is commodity, so it can be sold, traded and exchanged. It has the fluidity [2].

Information resources commercialization refers to individuals, businesses or organizations collect, deal with and make use of information resources by using a variety techniques and means, in order to achieve the value of information resources especially use value by selling information goods or providing paid information services (Figure 1).

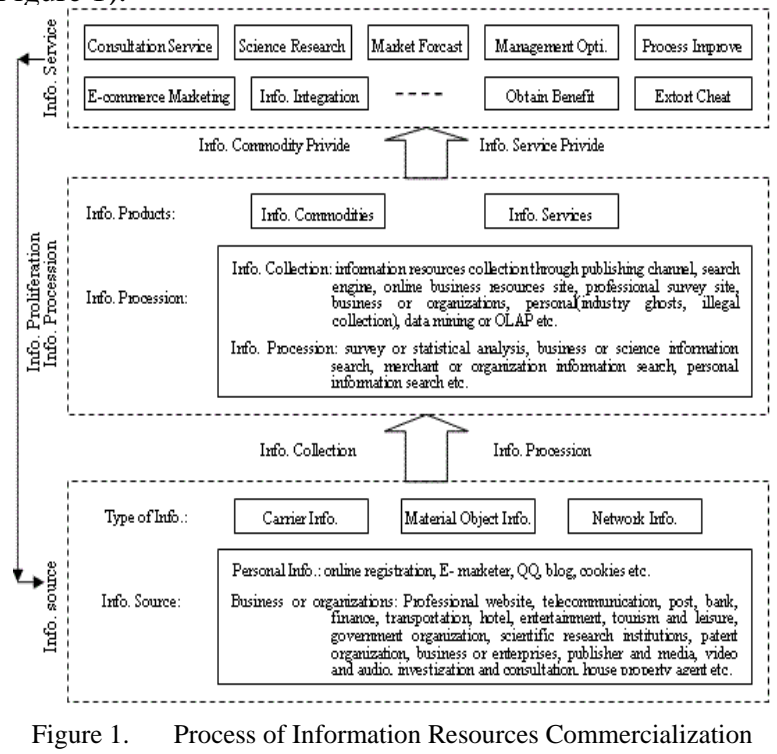


Information resources commercialization includes information collection, processing, development and utilization. It relates to information providers (individuals, businesses or organizations), information commodity or service providers (information collection, processing) and paid service objects (information goods or paid service users). So information resources commercialization appears obviously information economic characteristics [3].

\section{B. Driving Factors of Information Resources Commercialization}

According to the process of information resources commercialization, analyze the driving factors of information resources commercialization. There are many driving factors of information resources commercialization. The main factors show bellow:

(1) Politics drive. In recently years, national, industry and local governments have published many development plans and support policies for information resources in aspects of information resources commonly constructing and sharing, information disclosure, information innovation, IT safeguard and information services market pull etc. [7], speed up information resources constructing and sharing and commercialization development and utilization. These involves the integration and development utilization of network information resources, e-government information resources, education information resources, publishing and media information resources, library information resources, business information resources, nonprofit information resources, scientific and archival information resources, enterprise information resources. These preferential policies promote information resource commercialization and accelerate the process of social informatization.

(2) Modern information service industry development. Since the action plan of the modern service industry was officially launched in China in August 2007, the modern information service industry is as to be "a leading industry, a leader" in modern service industry is more and more important, especially the information content industry (animation, new media) based on a new generation information technology industry in the seven modern strategic emerging industries receives very "pet”. On foreign point of view, Japanese government is positioned information content industry as "positive revitalization new industry, the U.S. government has always insisted on the free flow principle of information and freedom competition principle of information market, and encourages the private enterprises to actively participate in the information content market competition. Therefore, the fast developing of modern information service industry promotes and accelerates the information resources commercialization.

(3) Marketization reform of scientific technology culture industry. In recent years, while the industry bodies such as scientific technology information service, publish media, union of digital library, government information service etc. are separated from main bodies and marketization reforming, a large number of market entities have appeared, such as paid information services, information resources access, information retrieval, market research reports, promote business information resources commercialization etc.

(4) Interest drive. In current information economy society, some businesses, enterprises, organizations or individuals illegally collect and sale various unauthorized information resources to obtain interest and profit, or make the common information resources be private. So interest drive is a driven element (which may be a legitimate) of information resources commercialization.

(5) Compensation for use of network information resources. Open characteristics is inherent of Network information resources. But, while the network technology is developing and network application is increasingly rich, the information exchanges have become increasingly frequent, embezzlement and abuse phenomenon is more and more serious. In order to preserve and highlight ownership of information resources, a lot of network information resources gradually close their opening door. This leads to pay for browse or download, and accelerates network information resources commercialization.

\section{INFORMATION RESOURCES COMMERCIALIZATION EXACERBATES PRIVACY INFORMATION LEAKAGE}

\section{A. Individual Information Security Status in Information} Resources Commercialization Process

Information resources commercialization promotes information resources development and utilization, and realizes the value and using value of information. But because the privacy information protection laws and regulations are not perfect in China, and organizations or individuals that own information resources lacks self-discipline, and market interest drives, technical measures are ineffective, citizens' safety awareness and skills are low. It leads to the illegal cases that invade individual privacy information can be heard without end in the process of information resources commercialization. It threatens national and social stability and has become a social focus problem.

Recently, we have made a survey on the current status of individual privacy information security and received a total of 11404 copies of questionnaires. We designed an investigation sheet which includes 4 aspects, 25 big items and 144 small items. We collect original data by using thematic website online survey method and questionnaire investigation method. According to statistical analysis and cross analysis to understand people's perception degree on the current status of individual privacy information protection and where they have left the privacy information. Survey shows that [5]: There are $91.39 \%$ people who always worry about their individual privacy information to be leaked. There are $85.7 \%$ people have been divulged their privacy and injured. There are only $5.32 \%$ people were able to actively take measures to protect their individual privacy information. There are $71.74 \%$ people have awareness but not to take special measures. There are $6.34 \%$ people consider that their privacy information needs to protect after their privacy information was leaked. There are $72.67 \%$ people have never realized their individual privacy 
information need to protect. This shows that: The security situation of individual privacy information is very worrying. These are the main reasons why major cases happened very often and increasingly rampant of invading individual privacy information in recent years in China.

\section{B. Invading Individual Privacy Information Acts in} Process of Information Resources Commercialization

The main acts to invade individual privacy information show bellow:

(1) Mine individual privacy information from public information resources. Such as: using data mining and analysis of OLAP technology to mine, analyze and collect individual privacy information from the public electronic journal databases, website databases, publishing media databases, scientific and technical information databases, professional website databases, industry website databases, business website databases etc.

(2) Use false network investigations to obtain individual privacy information. Such as: using the name of government, institution or organization to fake online survey, to trick the users trust, then to demand the people making online registration and fill in individual information, in order to collect individual privacy information.

(3) Use the Trojan, virus, plug-in program, network monitoring, IP tricks etc to invade, analyze and steal individual privacy information in recent years. They have become the main threaten for the individual privacy information security.

(4) Use Cookies and network log to obtain individual privacy information by analyzing the network activity trace information. Cookie is a double-edged sword, it brings convenience for users to browse internet, but it makes the individual internet browsing interest and preference be unmasked. Web log records the users' network activities trail, so it has become the main object to collect individual privacy information.

(5) "Industrial interior ghosts". In recent years, "industrial interior ghosts" have become the main reason to divulge individual privacy information, they sale and distribute individual privacy information, such as "bank interior ghosts", "railroad interior ghosts", "communication interior ghosts" etc. They seriously threat to the individual privacy information security.

\section{Measures to Protect Individual Privacy INFORMATION IN PROCESS OF INFORMATION RESOURCES COMMERCIALIZATION.}

In the process of information resources commercialization, because the main bodies of information resources collection, collection measures, development and utilization method, service objects are different, so the leakage way would be quite different for similar privacy information because the population characteristics and environment is different. Therefore, it is very difficulty to adopt focus measures and technical plan for the individual privacy information having different classes and different state. But the authors believe that the following four aspects are very important and effective.

\section{A. To Establish and Improve Relevant Laws and Regulations}

On relevant legislations of individual privacy information protection, United States, Europe, Korea, Japan and other countries are forerunners [6-9]. They have established a complete privacy legal protection system. But the current situation in China is [10]: It has nearly 40 laws, more than 30 department laws and regulations, and nearly 200 regulations relating to the of individual information protection. But they have following obvious shortcomings: not make specific definition to the meaning of privacy right, the infringer to assume the liability manner is not clear, the invasion responsibility is unidentified, the punishment is not enough, the risk cost of invasion privacy information behavior is too low etc. Therefore, to construct perfect the relevant laws and regulations is immediately, and it should be combined with the reality of our country as soon as possible to construct comprehensive laws on individual information privacy protection. Our suggestion is that it should have prospective on constructing the laws, should adequately predict and estimate the future development of society and the new invading acts, should consider the interest balance and coordination between information service providers, network application service providers, and the individual privacy right.

It is exciting that "personal information protection guide on information security technology, public and commercial information service system" has promulgated and implemented science 1st, Feb. 2013. This marks the safety protection of individual privacy information has laws.

\section{B. Strengthen Industry Self-Discipline, Standardize} Information Resources Development and Utilization

In the process of information resource commercialization, it should establish and improve self-discipline system, and standardize information resource development and utilization. Therefore, it is very important doing well three aspects bellow:

(1) The network organizations should play self management. It should establish the autonomous associations to protect individual privacy information, to standardize network activity.

(2) It should publish relation policies in industry interior to protect individual privacy information, especially for telecommunication, medical and other industry relating to sensitive individual privacy information, through strengthening industry self-discipline and legal constraints to reduce the probability of "industrial interior ghosts".

(3) At the same time, it should follow the following principles on collecting and using of individual privacy information [11]: clearly purpose, at least using, public informing, individual agreement, quality assurance, security, integrity and accountability etc.

\section{Improving individual privacy information protection consciousness and skills}

It is most important to improve individual privacy information protection consciousness and skills. The best 
method of protecting individual privacy information is "begin from me".

First, individuals must pay attention to protect themselves individual privacy information in their ideology, they should have good habits to use network application, comply with the safety operation rules, understand harm if their individual privacy information was leaked, and implement in the usual behaviors. Because that a lot of individual privacy information disclosure are caused imperceptibly.

Secondly, individuals should know a certain amount of safety technologies how to protect individual privacy information, such as having a good nurturance when they are online, do not open and reply unknown mail, stop network or shutdown at once; not easily fill in individual information (in addition to not have to, such as online banking, online payment ), do not use the account number and other special number to be password, clean-up the traces existing in computer or network including the account information, the sheet information and the "saved documents", log, document attributes, favorites in historical records etc., do not involuntary use USB disc in anywhere, to prevent trojan virus infection; not long time log on the movie and video game site, do not involuntary setup plug-in components, to filter and shield the threatening ActiveX, to hide or encrypt the secret information and prevent wiretapping and hacking, to download security BUG patches for system and application software, to install legitimate anti-virus software, refuse the threat site visiting, upgrade and shield the ports which are not used in time and turn off useless system services, do not storage and backup the important private documents randomly and transmit them in encryption, correct use and set Cookie, to install the software to protect privacy information and to process Cookies.

\section{Strengthen Construction of Social Credit System, Implement Credit Rating Open System}

In general, to construct a good honesty and credit social environment is helpful to protect individual privacy information. There are three aspects should be done bellow:

(1) To strengthen individual integrity and moral propaganda and education, to advocate good society fashion of respecting other's privacy.

(2) To establish and improve the social credit system. At present, there are four typical credit models adopted in information resources commercialization: intermediary model, guarantor model, Web site business model and delegation authority model.

(3) To strengthen and improve the credit management. First is to build inter-regional, cross-sectoral and inter-departmental unified credit information management system which is promoted and coordinated by the specific credit information management department of government. Second is that the special department of government should strengthen supervising for the credit agency. Third is that enterprises or individuals should fulfill reporting and updating of the obligation for their own credit information.

(4) Should fully play promoting role of government to build a national unified credit information management system supporting by special bunds, to realize credit information resources integration and fully open, to achieve credit information interconnection which is cross-departments, cross-industries, across-regions, to achieve network query all over the nation.

(5) To strengthen and improve the credit level of information service organs, and implement open credit rating system.

\section{CONCLUSIONS}

In process of information resource commercialization, because of the main bodies, collection ways, utilization methods, service objects of information resources are diversity, it causes the security risk factors of individual privacy information have diversity and complexity. Because the population characteristics and environment is often different, the leakage ways of similar privacy information are very different. Therefore, the security problem of individual privacy information is a complex systematic project, it involves construction and perfect of relation laws and regulations, standardized of industry self-discipline and information resources development and utilization, safety awareness and skills of individual, social credit environment, application research of network security technology and information security technology etc. Therefore it is difficult to give a universal, comprehensive protection strategy and the technical project. The authors think: The most simple and effective method is that citizens should pay attention to protect their privacy information in ideology, be high vigilant. Then the individual privacy information disclosure risk will be reduced greatly.

\section{ACKNOWLEDGMENT}

The authors would like to thank the editors and anonymous referrers give a lot of help in improving this paper. This research work was supported by the "Humanities and Social Science Planning Fund Project of Chinese Educational Ministry (No.12YJAZH093)”.

\section{REFERENCES}

[1] Feicheng Ma,Gang LI,Xianjin Zha. Information Resources Management. Wuhan University Process, 2001. p4-10. Wuhan, China.

[2] Guangjun Meng. Introduce to Information Resources Management. Scientific Press. 2008, p.26-34. Peking, China.

[3] Sanmao Chen, Lianmin Chen, Qin Deng. "Study on Economics of Information Resources”. Information Studies: Theory \& Application,Vol.26, No.2,2003.pp.126-128.

[4] Li Zhao( Director: Cuanfu Chen). "Choice of Public Policy to Promote Information Resources Public Access”. Wuhan University,2005.5.

[5] Survey Website of This Paper Supported Scientific Research Project.http://www.sojump.com/jq/ 1044838.aspx.

[6] Aimin Qi. “Analysis on Information Privacy Legislation in America”. Times Law, No.2. 2005, pp.109-115.

[7] Jinghong $\mathrm{Xu}$. "Legal Protection and Enlightenment on Network Privacy Right in European Union”. Information Studies:Theory \& Application,Vol.32, No.5. 2009,pp.117-120.

[8] Zonghao Lin. "Constitutional Protection of Privacy Rights in South Korea ”. Pacific Journal, No.7. 2009,pp.16-22. 
[9] Qing Xie. "Legal System and Enlightenment of Individual Information Protection in Japan”. Foreign Legal, No.6. 2006, pp.152-157.

[10] Shaofengh Guo, Peng Wu. GB on Individual Information Protection Will be Published, Information Should be Removed Immediately after was used [EB/OL].(2012-4-5)[2012-7-10]. http://www. ahwbls.com/Files/News578.htm.

[11] Jinghong Xu. "Self-discipline Protection, Current Situation, Problems and Countermeasures of Network Privacy Right in China". Library \& Information, No.5. 2009, pp.80-83. 